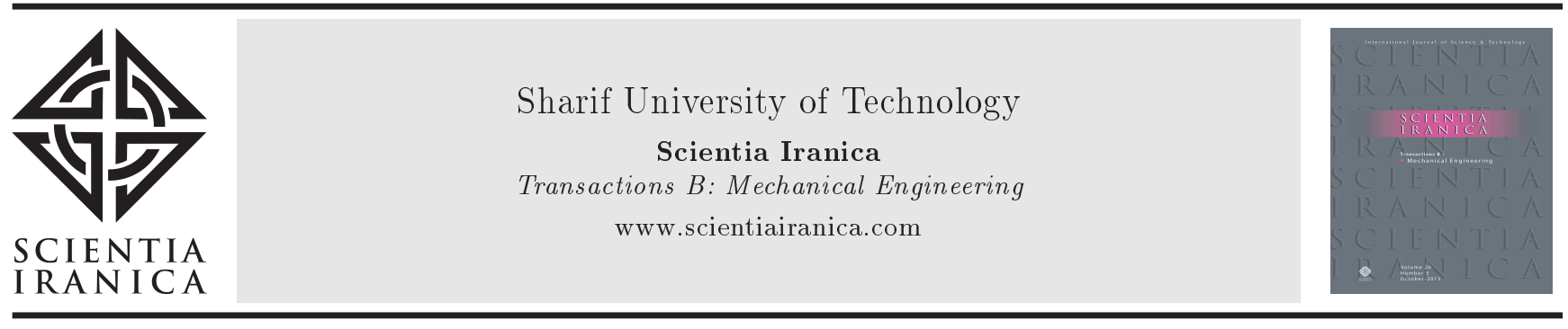

\title{
Investigating thermal performance of a partly sintered-wick heat pipe filled with different working fluids
}

\author{
M. Khalili ${ }^{a, b}$ and M.B. Shafii ${ }^{a, *}$ \\ a. Department of Mechanical Engineering, Sharif University of Technology, Tehran, P.O. Box 11155-9567, Iran. \\ b. Sharif Energy Research Institute (SERI), Tehran, P.O. Box 1459-7r7611, Iran. \\ Received 17 December 2014; received in revised form 28 October 2015; accepted 8 December 2015
}

\author{
KEYWORDS \\ Partly sintered-wick \\ heat pipe; \\ Circumferential \\ grooves; \\ Thermal resistance; \\ Working fluid; \\ Filling ratio; \\ Dry-out.
}

\begin{abstract}
Heat pipes are important cooling devices that are widely used to transfer high heat loads with low temperature differences. In this paper, thermal performance of a novel type of sintered-wick heat pipe, namely, partly sintered-wick heat pipe, was investigated. The heat pipe was filled with degassed water and acetone, as working fluids, and effects of filling ratio, orientation, and heat inputs were tested. Moreover, conditions at which dryout occurred were presented. The results showed that the best filling ratio for both working fluids is about $20 \%$. The heat pipe filled with water has better thermal performance than that filled with acetone; thus, the thermal resistances of the $20 \%$ water-filled heat pipe are approximately $7 \%, 27 \%$, and $75 \%$ lower than those of the $20 \%$ acetone-filled one in the vertical, horizontal, and reverse-vertical modes, respectively. This novel type of sinteredwick heat pipe has good thermal performance in the horizontal mode and can be used in no-gravity conditions, i.e. space applications.

(C) 2016 Sharif University of Technology. All rights reserved.
\end{abstract}

\section{Introduction}

Heat pipes are cooling devices that are widely used in electronic devices, satellites, air conditioning systems, etc. [1]. They have relatively high thermal conductivity and can replace aluminum structures with fin and other cooling devices with complicated geometry, because heat pipes can operate with low temperature difference in length [2]. They were first introduced by Gaugler in 1942 and further improved by Groover in 1964 [3]. High heat transfer capacity, ability to maintain a nearly constant evaporator temperature under different heat fluxes, and variety of designs in evaporator and condenser volumes make heat pipes efficient cooling systems [2].

*. Corresponding author. Tel.: +98 216616 5675;

Fax: +98216600 0021.

E-mail address: behshad@sharif.edu (M.B. Shafii)
Heat pipes are composed of three sections, namely, an evaporator, an adiabatic section, and a condenser. In the first step, heat is absorbed into the evaporating or boiling working fluid in the evaporator. Next, the generated vapor flows to the condenser side, where it releases heat and condenses back to the liquid state. Working liquid is continuously replenished at the evaporator via the porous lining that pumps liquid from the condenser by means of capillary force [4]. Because of the capillary force, heat pipes can be used in places where gravity is negligible (such as satellites) or even against gravity (where the evaporator is above the condenser).

Different parameters can affect the thermal performance of a heat pipe. Some of them are related to working fluid and its properties. Kumaresan et al. [3] tested a heat pipe with $\mathrm{CuO}$ nanofluids as working fluid. Their results showed that dispersion of nanoparticles in the base fluid increases the thermal 
conductivity of working fluid and the thermal performance of heat pipe. Kang et al. [5] reported that adding silver nanoparticles to water, compared with pure water as working fluid, decreases the temperature differences between pipe walls of a sintered-wick heat pipe.

Moreover, sintered wick structure affects the thermal performance of a sintered-wick heat pipe. Wang et al. [6] conducted some experiments on loop heat pipes with different wicks. Their results revealed that the wick of the heat pipe does affect the performance of the heat pipe. Wong et al. [7] also carried out several experiments on wicks sintered by irregular or spherical shaped powders with different size distributions. Their results illustrated that fine pores at the wick bottom help to sustain a thin water film under large heat loads that leads to better thermal performance and consequently makes large heat loads reachable. Liou et al. [8] reported that low wick permeability limited the reduction of evaporation resistance and prompted dry-out. Deng et al. [9] tested some types of powders and their effects on capillary performance. Their results showed that the irregular copper powder is better than the spherical one for the application in LHPs (loop heat pipes). The reason was attributed to the increased permeability and better capillary performance. Tsai and Lee [10] compared thermal performances of sintered heat pipes with different powder shapes and sizes. They reported that the spherical powder structures achieved twice the effective thermal conductivity of dendritic powder ones for each powder size. Furthermore, $\mathrm{Li}$ et al. [11] showed that the size of powder particles affects the performance of the heat pipe, and there exists an optimal size for particles in which the maximum operating power and minimum start-up temperature are reached. Jiang et al. [12] reported that sintering process influences thermal resistance, and porosity thickness and powder diameter affect heat transfer limit. Their results also illustrated that an optimal sintering process should keep balance between high porosity and proper radial shrinkage for mandrel pulling out.

In this work, a novel type of sintered-wick heat pipe, namely, partly sintered-wick heat pipe, was tested with degassed water and acetone as the working fluids. Thanks to its geometry, mandrel, and sintering fixture, the manufacturing procedure for this type of heat pipe is much simpler than the conventional types. In addition, mandrel can be easily removed after the sintering phase. These features make this heat pipe more economical than the annularly sintered type. This research is mainly focused on the thermal performance of this type of heat pipe under several conditions, such as different orientations and filling ratios for each working fluid.

\section{Experimentation}

\subsection{Heat pipe fabrication and its specifications}

In this proposed partly sintered-wick heat pipe, only one third of cross-sectional area was sintered. In addition, it had circumferential grooves (twenty four per one centimeter), with a depth and width of $0.15 \mathrm{~mm}$ in the evaporator and condenser sections.

In order to manufacture sintered wick, $0.75 \%$ wt mixture of Lithium stearate and $53-63 \mu \mathrm{m}$ spherical copper powder was used. The manufacturing procedure was similar to Reay et al. [13] sintering method described as follows: At first, tube was filled with powder while mandrel was located inside. Afterwards, it was heated in furnace at a temperature of $850^{\circ} \mathrm{C}$ and $50 \%$ Vol hydrogen and 50\% vol. nitrogen atmosphere for 30 minutes. After the tube was cooled and removed from the furnace, mandrel was brought out and the tube was resintered for another 30 minutes at the same conditions.

The outer diameter, total length, and casing thickness of the heat pipe were $15.87 \mathrm{~mm}, 250 \mathrm{~mm}$, and $0.68 \mathrm{~mm}$, respectively. One fourth of the total length was allocated to the evaporator section, one fourth to the condenser section, and the rest of it to the adiabatic section. Figure 1(a) and (b) show the circumferential grooves of the heat pipe before sintering and the crosssectional view of it after sintering, respectively.

Based on Archimedes' and imbibition's principle, the effective porosity of the wick was calculated to be $38.1 \%$.

\subsection{Experimental setup and procedure}

Experimental setup consisted of test section, electrical power supply, two digital multimeters, five thermocouples, data acquisition system, and thermally controlled water jacket as shown in Figure 2. Five K-type thermocouples were used to measure temperatures at different locations. Two thermocouples were attached to the evaporator section, two others were installed on the condenser section, and the last one was placed on the adiabatic section. The mean temperatures in the evaporator and condenser sections were used to

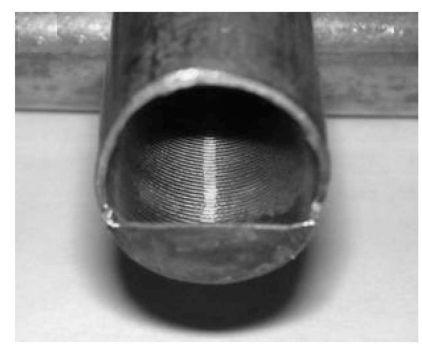

(a)

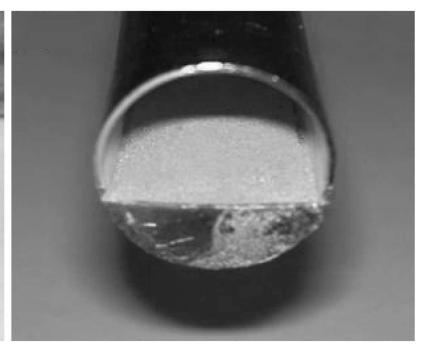

(b)
Figure 1. Cross-sectional view of the partly sintered-wick heat pipe: (a) Before sintering, and (b) after sintering. 


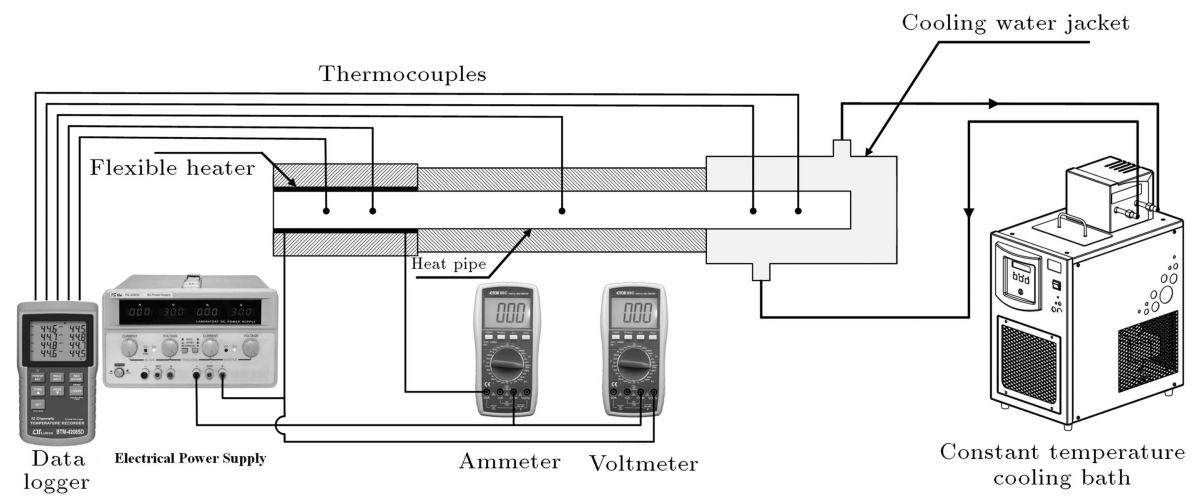

Figure 2. Schematic diagram of the experimental set-up.

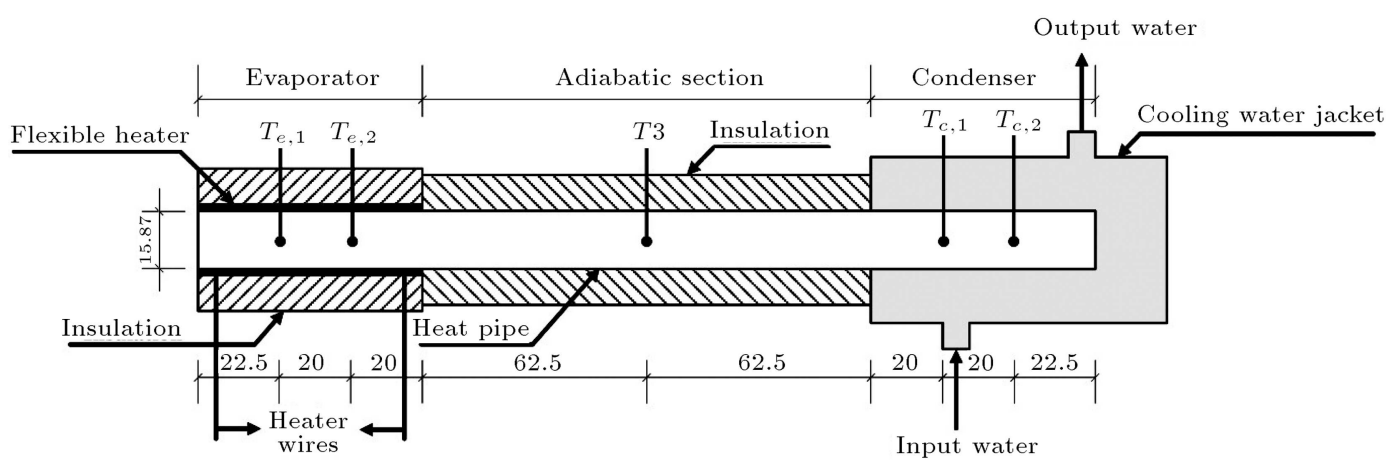

Figure 3. Schematic diagram of thermocouples locations of test section.

determine the thermal resistances. Thermal resistance is a good criterion to compare thermal performances of water and acetone as working fluids. Figure 3 shows schematic diagram of the heat pipe along with the thermocouples locations.

A flexible resistance heater was applied to heat up the evaporator section of the heat pipe. An electrical power supply was implemented to control the electrical power in order to supply a uniform heat input to the evaporator. The input heat flux was determined by multiplying the amperage and voltage measured by two multimeters. A constant volumetric flow rate of cooling water with fixed temperature was circulated around the condenser section in order to cool it down. The adiabatic and the evaporator sections were wrapped by $10 \mathrm{~mm}$ of thick glass wool, and then covered by 20 $\mathrm{mm}$ of elastomeric foam insulation.

The heat pipe was vacuumed and then filled with degassed water and acetone as working fluids at different filling ratios to evaluate its thermal performance. The filling ratios were $10 \%, 20 \%, 30 \%$, and $45 \%$, which are briefly denoted by the symbols FR10, FR20, FR30, and FR40, respectively. Moreover, different orientations of the heat pipe were tested to investigate the effect of gravity on its thermal performance. Heat input increased from $5 \mathrm{~W}$ to $160 \mathrm{~W}$. After setting heat input and reaching steady-state condition, temperatures were recorded and thermal resistances were calculated.
The performance test of the heat pipe was consecutively conducted according to the orientation angle of the pipe with respect to the horizon in the following modes for each working fluid:

1. Vertical mode: The condenser was at the top of the heat pipe, and the evaporator was at the bottom of it;

2. Horizontal mode: The evaporator and condenser were located at the same height.

Due to asymmetric structure of the wick in the partly sintered heat pipe introduced in the present study, the performance test in the horizontal mode was itself comprised of two distinct modes according to the position of the wick:

a) Horizontal-up mode: The sintered part of the wick was located at the top of the heat pipe;

b) Horizontal-down mode: This mode was similar to the horizontal-up mode, except that the sintered part of the wick was located at the bottom of the heat pipe.

Figure 4(a) and (b) show schematic diagrams of this partly sintered-wick heat pipe when wick is at the top or at the bottom of the pipe, respectively;

3. Reverse-vertical mode: The condenser was located at the bottom of the heat pipe, and the evaporator was at the top of it. 


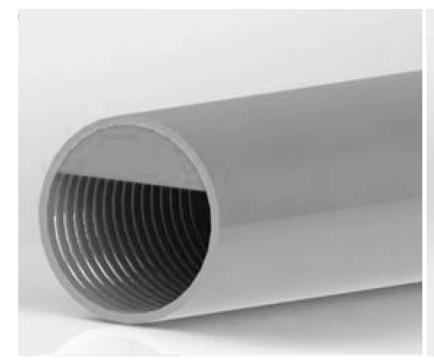

(a)

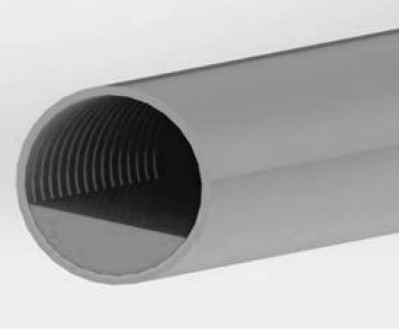

(b)
Figure 4. Schematic diagrams of (a) the partly sintered-wick heat pipe, when wick is at the top, and (b) bottom of the pipe.

\subsection{Data reduction}

In this paper, the results are presented based on thermal resistances. Thermal resistance can be defined as follows:

$$
\begin{aligned}
& R=\frac{\Delta T}{Q}, \\
& \Delta T=T_{e}-T_{c},
\end{aligned}
$$

where $R$ denotes the mean thermal resistance, $Q$ is the heat input in the evaporator section, $\Delta T$ is the temperature difference between the evaporator and condenser sections, and $T_{e}$ and $T_{c}$ are the average temperatures in the evaporator and condenser, respectively.

\subsection{Uncertainty analysis}

The accuracy of instruments affects uncertainties of experimental results [14]. The accuracy of thermocouples, voltage, and amperage reading were approximately $0.5^{\circ} \mathrm{C}, 0.1 \mathrm{~V}$, and $0.01 \mathrm{~A}$, respectively. The voltage and amperage uncertainties are taken in heat input uncertainty calculation.

$$
\frac{\Delta Q}{Q}=\left[\left(\frac{\Delta V}{V}\right)^{2}+\left(\frac{\Delta I}{I}\right)^{2}\right]^{\frac{1}{2}}
$$

Heat input and temperature difference between the evaporator and condenser affect the thermal resistance uncertainty.

$$
\frac{\Delta R}{R}=\left[\left(\frac{\Delta Q}{Q}\right)^{2}+\left(\frac{\Delta(\Delta T)}{\Delta T}\right)^{2}\right]^{\frac{1}{2}} .
$$

Based on the equations above, the maximum uncertainties in all tests for the heat inputs and the thermal resistances are $3.7 \%$ and $9.6 \%$, respectively.

\section{Results and discussion}

Since the heat pipes are two-phase heat transfer devices, the thermophysical properties of the working fluid affect their performance. Water and acetone have different thermophysical properties at a specific temperature, which can lead to better performance of one of the fluids under specific conditions and according to the input heat. Acetone has a lower boiling point than water, which causes the evaporation in the heat pipe with this fluid to occur at lower heat inputs. However, due to this reason, in higher heat inputs, the probability of dry-out phenomenon increases in the heat pipe when using acetone. On the other hand, the surface tension of water is higher than that of acetone, which improves the capillary force for transferring the working fluid from the condenser to the evaporator. Table 1 presents the properties of water and acetone at different temperatures for the sake of comparison. Thus, by using these two fluids whose properties widely differ, the effects of various thermophysical properties, such as the boiling point and the capillary force that is the main factor of movement, can be examined in various operation conditions. In addition, it is worth noting that these fluids are used in the conventional heat pipes for space applications or cooling of electronic devices and both fluids are consistent with copper as the casing material [15].

Figures 5 through 8 show thermal resistance versus heat input for water-filled heat pipe at different filling ratios and different modes.

The results show that thermal resistance decreases as heat input increases, which is due to nucleate boiling occurrence at higher heat inputs [17]. Also, at low heat input/temperature, the surface tension between the solid-liquid interfaces is high and this effect will be subsequently reduced with increasing heat input. Moreover, the film thickness of liquid layer in the evaporator section is high at low heat inputs. This creates high thermal resistance, but the film thickness

\begin{tabular}{|c|c|c|c|c|c|c|}
\hline & \multicolumn{3}{|c|}{ Water } & \multicolumn{3}{|c|}{ Acetone } \\
\hline & $\mathbf{0}^{\circ} \mathrm{C}$ & $40^{\circ} \mathrm{C}$ & $80^{\circ} \mathrm{C}$ & $\mathbf{0}^{\circ} \mathrm{C}$ & $40^{\circ} \mathrm{C}$ & $80^{\circ} \mathrm{C}$ \\
\hline Vapor pressure (bars) & 0.006 & 0.074 & 0.475 & 0.1 & 0.6 & 2.15 \\
\hline Latent heat $(\mathrm{kJ} / \mathrm{kg})$ & 2502 & 2406 & 2309 & 564 & 536 & 495 \\
\hline Liquid density $\left(\mathrm{kg} / \mathrm{m}^{3}\right)$ & 1000 & 992 & 972 & 812 & 768 & 719 \\
\hline Liquid viscosity $\left(10^{3}\right.$ Pa.S $)$ & 1.75 & 0.655 & 0.329 & 0.395 & 0.269 & 0.192 \\
\hline Surface tension $\left(10^{2} \mathrm{~N} / \mathrm{m}\right)$ & 7.55 & 6.95 & 6.17 & 2.62 & 2.12 & 1.62 \\
\hline
\end{tabular}
decreases with the increase in heat input $[3,18]$.

In the vertical mode, the heat pipe works like a

Table 1. Comparison between the thermophysical properties of the used working fluids at different temperatures [15,16]. 


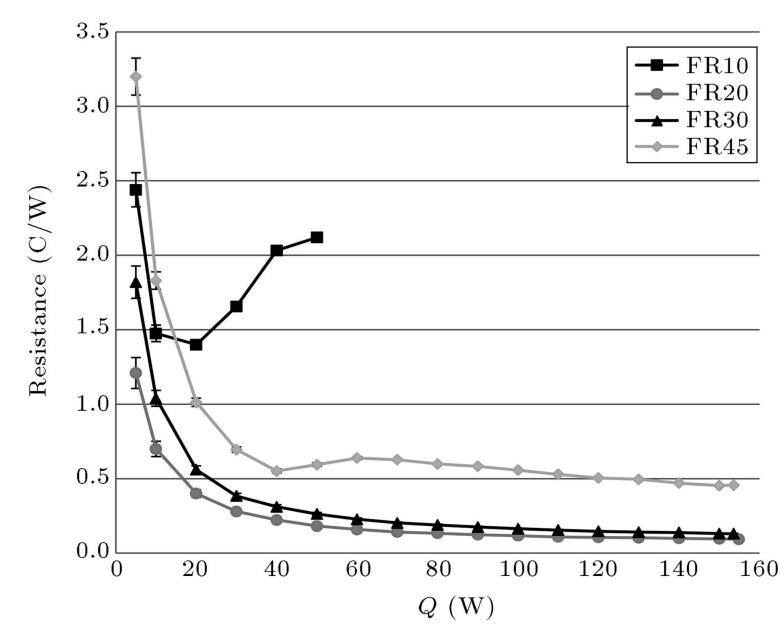

Figure 5. Thermal resistance vs. heat input for water-filled heat pipe in the vertical mode.

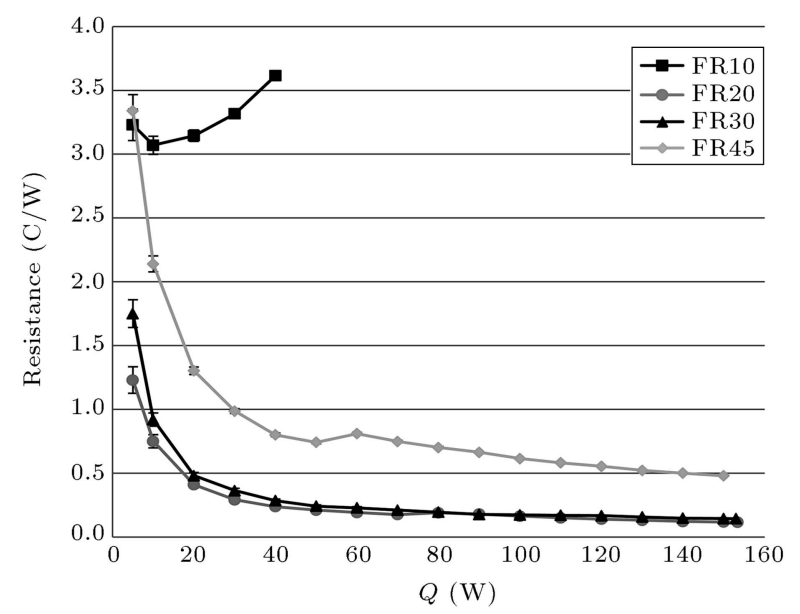

Figure 6. Thermal resistance vs. heat input for water-filled heat pipe in the horizontal-up mode.

thermosyphon and both gravity and capillary forces have the same direction and boost the thermal performance of the heat pipe. Since two third of the cross-section has no wick structure, the average internal thermal resistances of the evaporator and condenser sections are low and as a result, vaporization and condensation occur rapidly. All these conditions lead to a good thermal performance and delayed dry-out occurrence at higher heat inputs.

As seen in Figure 5, in the vertical mode, the water-filled heat pipe has the highest performance at the filling ratio of FR20 (i.e. 20\%) such that the average thermal resistance at this filling ratio is approximately $88 \%, 30 \%$, and $70 \%$ lower than those of FR10, FR30, and FR45 filling ratios, respectively.

In the horizontal-up mode, circumferential grooves conduct condensed liquid against gravity toward the wick located at the top and from there, the liquid moves to the evaporator by capillary force through the sintered wick. Similar to the vertical

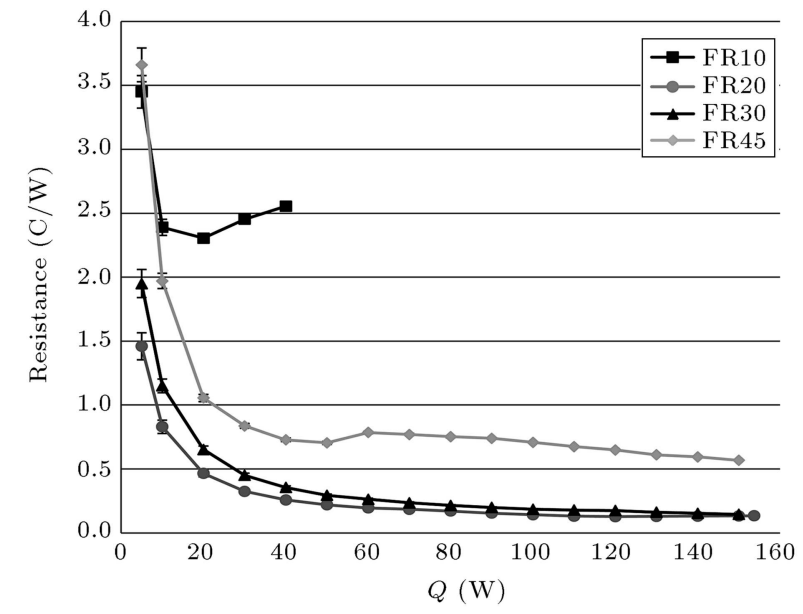

Figure 7. Thermal resistance vs. heat input for water-filled heat pipe in the horizontal-down mode.

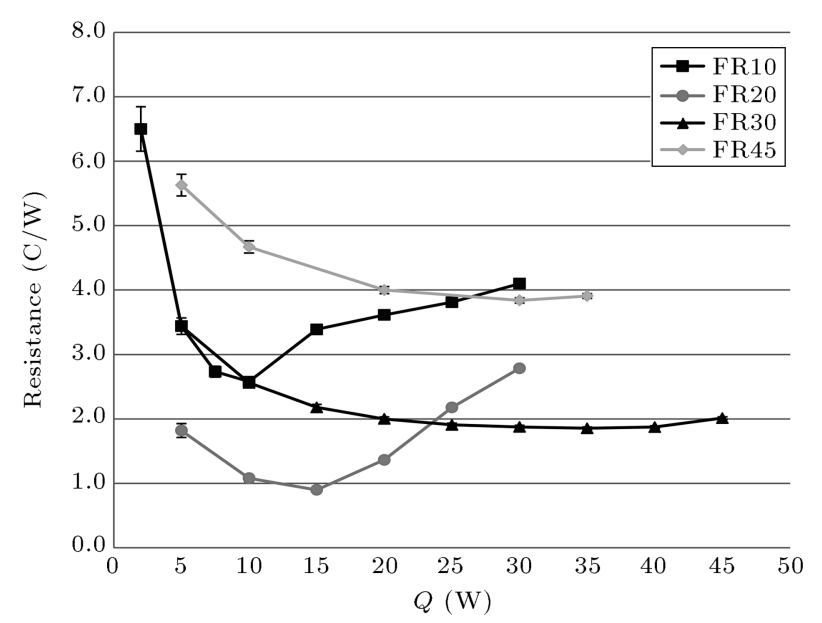

Figure 8. Thermal resistance vs. heat input for water-filled heat pipe in the reverse-vertical mode.

mode, in the horizontal-up mode, the heat pipe has the minimum thermal resistances at FR20 filling ratio and the average thermal resistance at this filling ratio compared with FR10, FR30, and FR45 filling ratios is about $93 \%, 17 \%$, and $71 \%$ lower, respectively.

The horizontal-down mode is similar to the horizontal-up mode, except that the sintered wick is located at the bottom of the pipe. In this mode, condensed liquid in the upper part of the condenser falls down over the wick by gravitational force and gets pulled to the evaporator through the wick due to the capillary force. In this mode, the average thermal resistance at FR20 filling ratio is approximately 90\%, $25 \%$, and $70 \%$ lower than those of FR10, FR30, and FR45 filling ratios, respectively.

In the reverse-vertical mode, the pressure difference between the evaporator and condenser sections pushes the generated vapor from the evaporator to the condenser and then the vapor becomes liquid by heat dissipation in the condenser. The condensed 
liquid moves against gravity to the evaporator through the wick due to the capillary action. In order for the heat pipe to operate properly in this mode, the capillary force should overcome pressure losses as well as the gravity force. Hence, in this mode, the thermal performance deteriorates in comparison with other modes and dry-out occurs at lower heat inputs due to the lack of liquid in the evaporator. In this mode, the FR20 filling ratio results in better thermal performance for low heat inputs. For high heat inputs, the FR30 filling ratio has the lowest average thermal resistance. The results show that thermal resistances are more sensitive to filling ratio changes in the reverse-vertical mode than other modes and in this mode, differences between thermal resistances at different filling ratios are clear. In other modes, this sensitivity is lower; especially at FR20 and FR30 filling ratios and high heat inputs, thermal resistances have small differences in the vertical, horizontal-up, and horizontal-down modes.

The results show that dry-out occurs at higher heat inputs as filling ratio increases. For example, in the reverse-vertical mode at FR10, FR20, and FR30 filling ratios, dry-out occurs at $10 \mathrm{~W}, 15 \mathrm{~W}$, and $35 \mathrm{~W}$, respectively. At lower filling ratios, total liquid inventory in the heat pipe is small. Thus, at high heat inputs, evaporation rates are higher than condensation rates and this leads to inadequate liquid for evaporation in the evaporator.

Figures 9 through 12 present the results for acetone-filled heat pipe at different filling ratios and different modes.

As shown in Figures 9 through 12, the trends of the thermal resistance curves for acetone-filled heat pipe are similar to curves of water-filled heat pipe shown in Figures 5 through 8, but thermal resistances of acetone are higher than those of water in the same conditions. In addition, the results show that

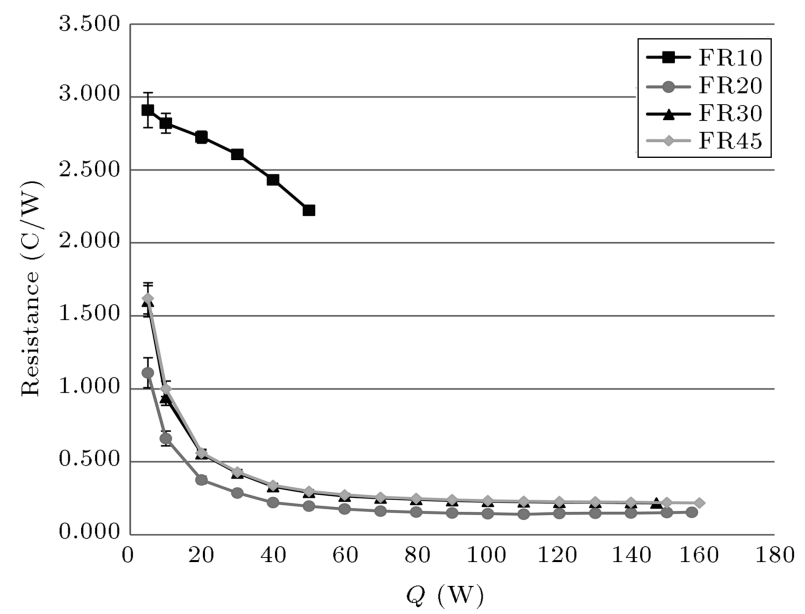

Figure 9. Thermal resistance vs. heat input for acetone-filled heat pipe in the vertical mode. the acetone-filled heat pipe is less sensitive to filling ratio changes in different modes than water-filled heat pipe. This fact is clearly obvious in the reverse-vertical

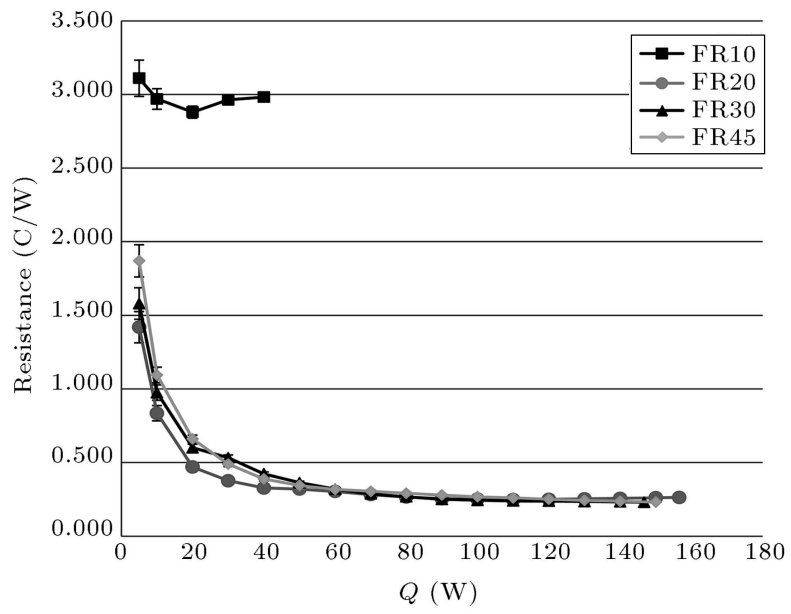

Figure 10. Thermal resistance vs. heat input for acetone-filled heat pipe in the horizontal-up mode.

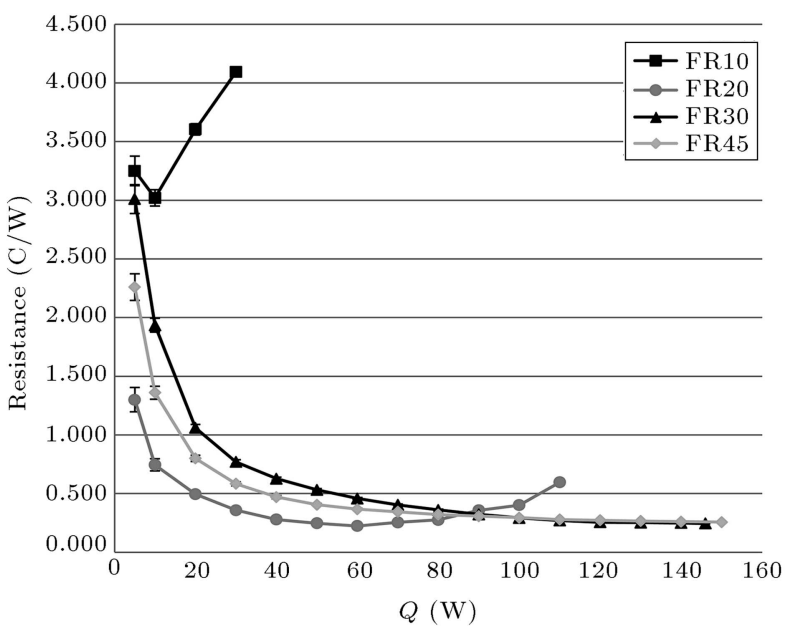

Figure 11. Thermal resistance vs. heat input for acetone-filled heat pipe in the horizontal-down mode.

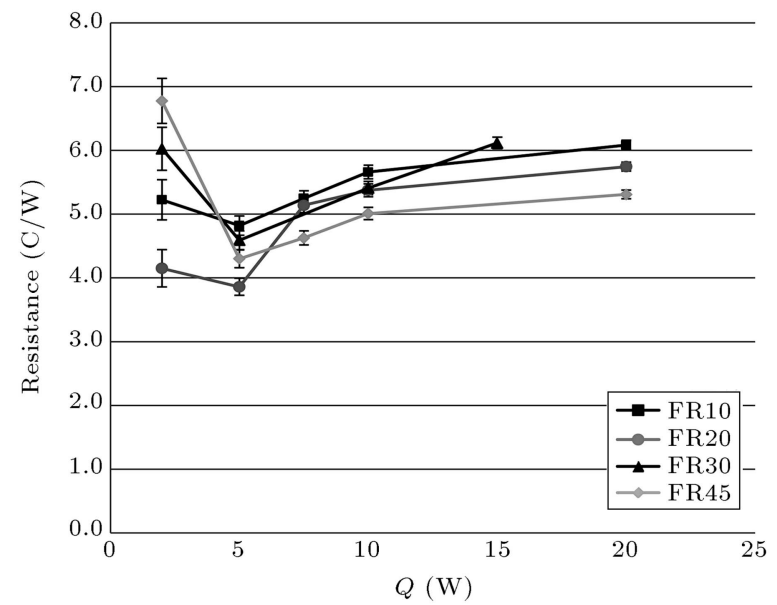

Figure 12. Thermal resistance vs. heat input for acetone-filled heat pipe in the reverse-vertical mode. 
mode as thermal resistances of the acetone-filled heat pipe at different filling ratios have small differences compared with the heat pipe filled with water at this mode.

At low filling ratios, due to inexistence of sufficient liquid for evaporation in the evaporator and increase in the probability of the dry-out phenomenon, the performance of the heat pipe deteriorates. On the other hand, at higher filling ratios, incomplete evaporation occurs due to existence of a large amount of liquid in the pipe, and the motion of the fluid is impeded. As a result, the thermal resistance increases and the performance of the heat pipe deteriorates. Thus, an optimum filling ratio exists for the heat pipe [19]. As shown in Figures 9 and 10, in the vertical and horizontal-up modes, the heat pipe filled with acetone, similar to the water-filled one, has better thermal performance at FR20 filling ratio than at other filling ratios, so that the average thermal resistance at this filling ratio compared with FR10, FR30, and FR45 filling ratios is approximately $91 \%, 33 \%$, and $34 \%$ lower in the vertical mode, and $88 \%, 9 \%$, and $13 \%$ lower in the horizontal-up mode, respectively.

Figure 11 indicates that in the horizontal-down mode, FR20 filling ratio has the minimum thermal resistances up to $90 \mathrm{~W}$ of heat input and after that, thermal resistance of the heat pipe increases due to dry-out occurrence. At high heat inputs, filling ratios of FR30 and FR45 show better thermal performances.

In the reverse-vertical mode, the acetone-filled heat pipe has better thermal performance at FR20 filling ratio than at other filling ratios at low heat inputs. At high heat inputs, FR45 filling ratio has the minimum thermal resistances. At FR45 filling ratio, distance between free surface of liquid inside the pipe and the evaporator is smaller; thus, the liquid should move in the smaller path through the wick to reach the evaporator. Hence, the low capillary force in the reverse-vertical mode, due to low surface tension of acetone, can be compensated.

Inasmuch as, in general and in sum, the best filling ratio in different modes both for water and acetone is FR20 (i.e. 20\%), in what follows, the performances of the heat pipe at this filling ratio and under various conditions are compared so that the effect of various factors on the performance of the heat pipe at a specific filling ratio can be determined.

Figures 13 and 14 compare thermal resistances of different modes at FR20 filling ratio for water and acetone, respectively.

Due to the gravity force effects, the minimum and maximum thermal resistances occur in the vertical and reverse-vertical modes, respectively. In the reverse-vertical mode, return of condensed fluid to the evaporator is difficult due to reverse gravity effect [20].
Because of small length and width of circumferential grooves and, therefore, enhanced capillary action, the performance of the evaporator and condenser improves. Moreover, as mentioned previously, since there is no wick in two third of the cross-section, the average internal thermal resistance between fluid and heat transfer area is low. These conditions provide good status for this heat pipe to have desired performance in the horizontal modes. The results illustrate that at FR20 filling ratio and vertical mode, the average thermal resistance of water-filled heat pipe is approximately $13 \%, 17 \%$, and $87 \%$ lower than those in the horizontal-up, horizontal-down, and reverse-vertical modes, respectively. These differences for acetone are about $34 \%, 43 \%$, and $95 \%$, respectively.

Based on the results, thermal resistances in the horizontal-up and horizontal-down modes are approximately the same, particularly when water is used as the working fluid. Hence, it can be concluded that gravity

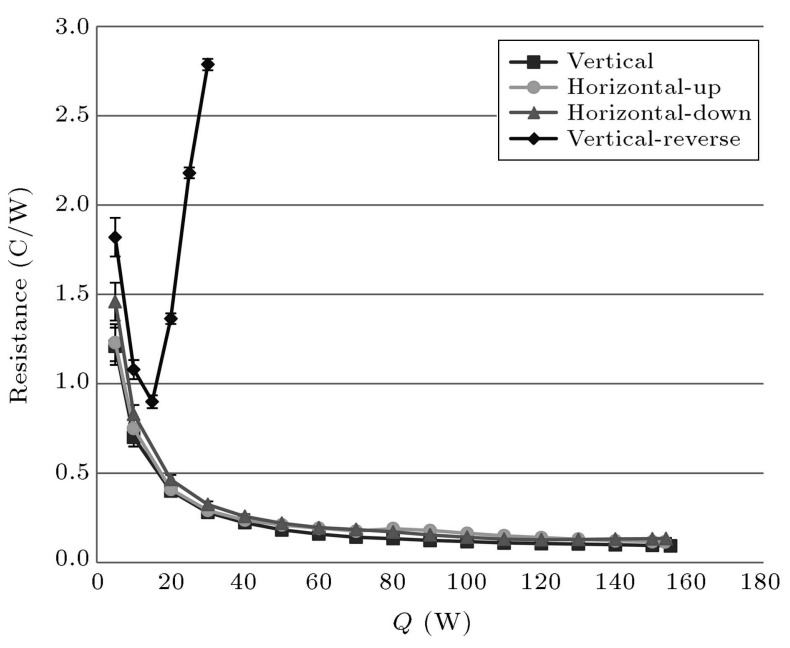

Figure 13. Thermal resistance vs. heat input at FR20 filling ratio of water.

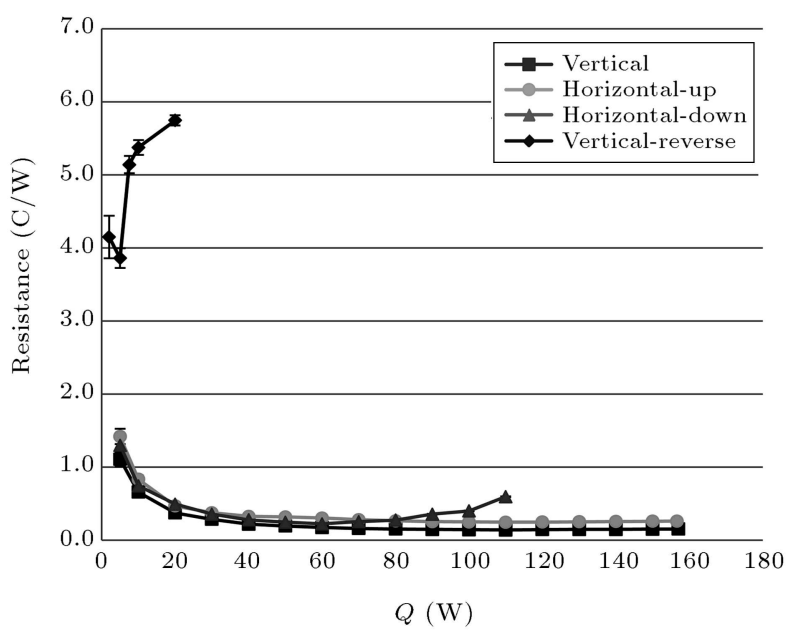

Figure 14. Thermal resistance vs. heat input at FR20 filling ratio of acetone. 
direction has virtually a minor effect on the thermal performance in the horizontal modes. Furthermore, thermal resistances of the water-filled heat pipe in the horizontal modes are just slightly higher than those of in the vertical mode. This indicates a desired thermal performance of this type of heat pipe at zero gravity conditions, such as space applications.

As seen in Figures 13 and 14, at FR20 filling ratio, which is the best filling ratio among all filling ratios, for water in the vertical mode, the minimum thermal resistance occurs at heat inputs above $150 \mathrm{~W}$, which is less than $0.093 \frac{{ }^{\circ} \mathrm{C}}{\mathrm{W}}$. For acetone-filled heat pipe, the minimum thermal resistance at FR20 filling ratio is about $0.14 \frac{{ }^{\circ} \mathrm{C}}{\mathrm{W}}$ at a heat input of $110 \mathrm{~W}$. Based on the results, thermal resistances of this heat pipe have the same order of magnitude as those presented by Kumaresan et al. [3].

Figures 15 and 16 present thermal resistances of the heat pipe for water and acetone at FR20 filling ratio

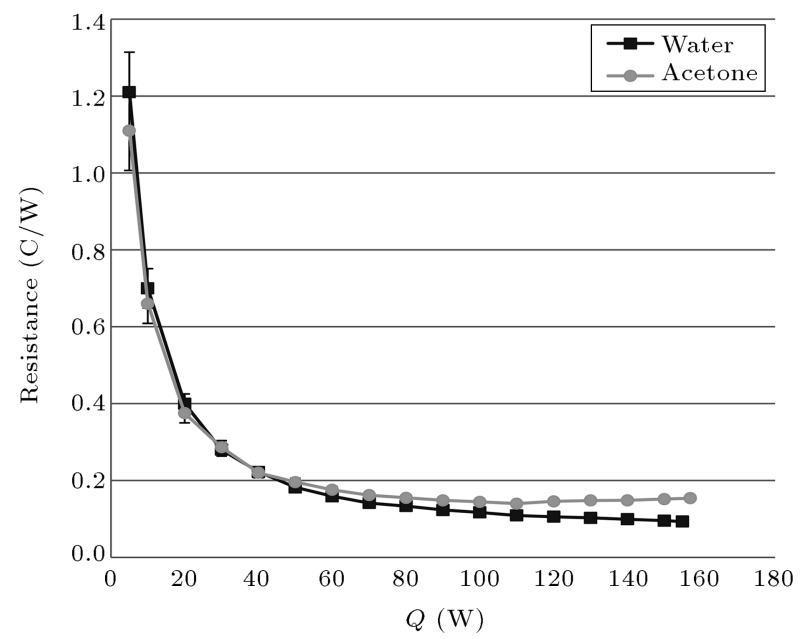

Figure 15. Thermal resistance vs. heat input for water and acetone at FR20 filling ratio for vertical mode.

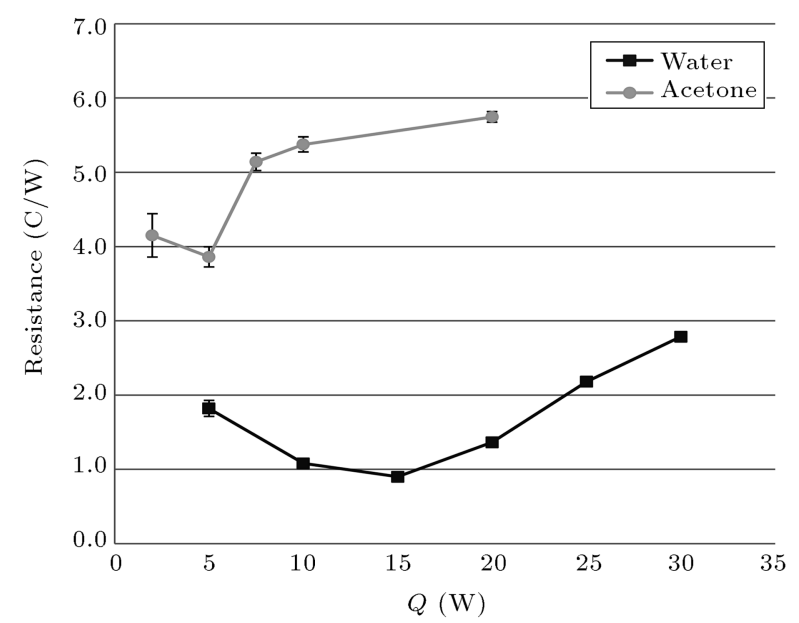

Figure 16. Thermal resistance vs. heat input for water and acetone at FR20 filling ratio for reverse-vertical mode. for vertical (in which heat pipe has the best thermal performance) and reverse-vertical (in which heat pipe has the worst thermal performance) modes, respectively. Comparison of these figures clearly demonstrates the effect of working fluid on the thermal resistance.

As shown in Figure 15 in the vertical mode, at high heat inputs, acetone has slightly poorer thermal performance than water. However, at low heat inputs, acetone has approximately the same thermal resistance as that of water within experimental errors due to its lower boiling temperature. In the reverse-vertical mode, for the same conditions, water shows better thermal performance for all heat inputs, because, as shown in Table 1, the surface tension of water is higher than that of acetone, which leads to higher capillary force in the sintered wick. Our results indicate that thermal resistances of the $20 \%$ water-filled heat pipe are approximately $7 \%, 27 \%$, and $75 \%$ lower than those of the $20 \%$ acetone-filled one in the vertical, horizontal, and reverse-vertical modes, respectively.

\section{Conclusions}

In this research, a novel type of sintered-wick heat pipe, the partly sintered-wick heat pipe, was tested with degassed water and acetone as working fluids. Based on the results, the following conclusions can be drawn:

- Dry-out occurs at higher heat inputs by increasing filling ratios;

- The best thermal performance is observed around $20 \%$ filling ratio and the vertical mode for both working fluids;

- The thermal resistance of acetone-filled heat pipe is less sensitive to filling ratio changes than that of water-filled heat pipe;

- Wick location in the horizontal modes has little effect on the thermal resistance, particularly when water is used as the working fluid;

- The thermal resistances of water-filled heat pipe in the horizontal modes are just slightly higher than those in the vertical mode. This indicates a desired thermal performance of this type of heat pipe at zero gravity conditions, such as space applications;

- In the vertical mode and at high heat inputs, water shows better thermal performance as working fluid than acetone. However, at lower heat inputs, water has approximately the same thermal resistance as that of acetone within experimental errors;

- In the reverse-vertical mode, for the same conditions, water has better thermal performance for all heat inputs than acetone due to its higher surface tension that leads to higher capillary force in the sintered wick; 
- The thermal resistances of the $20 \%$ water-filled heat pipe are approximately $7 \%, 27 \%$, and $75 \%$ lower than those of the $20 \%$ acetone-filled one in the vertical, horizontal, and reverse-vertical modes, respectively.

\section{Nomenclature}

$\begin{array}{ll}I & \text { Current }(\mathrm{A}) \\ Q & \text { Heat input }(\mathrm{W}) \\ R & \text { Thermal resistance }\left({ }^{\circ} \mathrm{C} / \mathrm{W}\right) \\ T & \text { Temperature }\left({ }^{\circ} \mathrm{C}\right) \\ V & \text { Voltage }(\mathrm{V})\end{array}$

\section{Greek letters}

$\Delta \quad$ Increment

\section{Subscripts}

$\begin{array}{ll}c & \text { Condenser } \\ e & \text { Evaporator } \\ \text { tot } & \text { Total }\end{array}$

\section{References}

1. Ahmadzadehtalatapeh, M. "An air-conditioning system performance enhancement by using heat pipe based heat recovery technology", Scientia Iranica, 20(2), pp. 329-336 (2013).

2. Peterson, G.P. and Ortega, A. "Thermal control of electronic equipment and devices", In Advances in Heat Transfer, 20, pp. 181-314, Pergamon Press, New York, US (1990).

3. Kumaresan, G., Venkatachalapathy, S. and Asirvatham, L. "Experimental investigation on enhancement in thermal characteristics of sintered wick heat pipe using $\mathrm{CuO}$ nanofluids", International Journal of Heat and Mass Transfer, 72, pp. 507-516 (2014).

4. Weibel, J. and Garimella, S. "Visualization of vapor formation regimes during capillary-fed boiling in sintered-powder heat pipe wicks", International Journal of Heat and Mass Transfer, 55(13-14), pp. 34983510 (2012).

5. Kang, S., Wei, W., Tsai, S. and Huang, C. "Experimental investigation of nanofluids on sintered heat pipe thermal performance", Applied Thermal Engineering, 29(5-6), pp. 973-979 (2009).

6. Wang, D., Liu, Z., He, S., Yang, J. and Liu, W. "Operational characteristics of a loop heat pipe with a flat evaporator and two primary biporous wicks", International Journal of Heat and Mass Transfer, 89, pp. 33-41 (2015).

7. Wong, S., Liou, J. and Chang, C. "Evaporation resistance measurement with visualization for sintered copper-powder evaporator in operating flat-plate heat pipes", International Journal of Heat and Mass Transfer, 53(19), pp. 3792-3798 (2010).
8. Liou, J., Chang, C., Chao, C. and Wong, S. "Visualization and thermal resistance measurement for the sintered mesh-wick evaporator in operating flat-plate heat pipes", International Journal of Heat and Mass Transfer, 53(7-8), pp. 1498-1506 (2010).

9. Deng, D., Liang, D., Tang, Y., Peng, J., Han, X. and Pan, M. "Evaluation of capillary performance of sintered porous wicks for loop heat pipe", Experimental Thermal and Fluid Science, 50, pp. 1-9 (2013).

10. Tsai, Y. and Lee, C. "Experimental study of evaporative heat transfer in sintered powder structures at low superheat levels", Experimental Thermal and Fluid Science, 52, pp. 230-238 (2014).

11. Li, H., Wang, X., Liu, Z., Tang, Y., Yuan, W., Zhou, R. and Li. Y. "Experimental investigation on the sintered wick of the anti-gravity loop-shaped heat pipe", Experimental Thermal and Fluid Science, 68, pp. 689-696 (2015).

12. Jiang, L., Tang, Y., Zhou, W., Jiang, L., Xiao, T., Li, Y. and Gao, J. "Design and fabrication of sintered wick for miniature cylindrical heat pipe", Transactions of Nonferrous Metals Society of China, 24(1), pp. 292301 (2014).

13. Reay, D., Kew, P. and McGlen, R., Heat pipes: Theory, Design and Applications, 6th Edn., ButterworthHeinemann, Oxford, UK (2014).

14. Moffat, R. "Describing the uncertainties in experimental results", Experimental Thermal and Fluid Science, 1(1), pp. 3-17 (1988).

15. Lee, H., Thermal Design: Heat Sinks, Thermoelectrics, Heat Pipes, Compact Heat Exchangers, and Solar Cells, Wiley, New Jersey, US (2010).

16. Incropera, F., DeWitt, D., Bergman, T. and Lavine, A., Fundamentals of Heat and Mass Transfer, 7th Edn., Wiley, New York, US (2011).

17. Grubb, K. "CFD Modeling of a Therma-Base (TM) Heat Sink", 8th International FLOTHERM User Conference, Las Vegas, US, pp. 13-14 (1999).

18. Kumaresan, G., Venkatachalapathy, S., Asirvatham, L. and Wongwises, S. "Comparative study on heat transfer characteristics of sintered and mesh wick heat pipes using $\mathrm{CuO}$ nanofluids", International Communications in Heat and Mass Transfer, 57, pp. 208-215 (2014).

19. Chen, J. and Chou, J. "Cooling performance of flat plate heat pipes with different liquid filling ratios", International Journal of Heat and Mass Transfer, 77, pp. 874-882 (2014).

20. Taslimifar, M., Mohammadi, M., Afshin, H., Saidi, M.H. and Shafii, M.B. "Overall thermal performance of ferrofluidic open loop pulsating heat pipes: An experimental approach", International Journal of Thermal Sciences, 5, pp. 234-241 (2013). 


\section{Biographies}

Mohammad Khalili obtained his $\mathrm{PhD}$ degree in Mechanical Engineering from sharif University of Technology, Tehran, Iran, in 2016. He received BSc degrees in Mechanical Engineering and Petroleum Engineering (Double-magor), in 2006, and MSc degree in 2009 from Sharif University of Technology. His research interests include experimental tests, heat pipes (such as thermosyphons, sintered-wick heat pipes, loop heat pipes, etc.), heat exchangers, oil formation damage, asphaltene precipitation and deposition in oil reservoirs, etc.
Mohammad Behshad Shafii received the PhD degree in Mechanical Engineering from Michigan State University, East Lansing, in 2005. He is currently an Associate Professor in the Department of Mechanical Engineering, Sharif University of Technology, Tehran, Iran. His research interests include heat pipes (such as thermosyphons, pulsating and rotating types, loop heat pipes, etc.), fluid diagnostic techniques (molecular tagging velocimetry, particle image velocimetry, and laser-induced fluorescence), heat transfer and phase change phenomena, micro-pumps, solar energy, etc. 